\title{
Seguimento de Jesus e identidade cristã
}

\author{
Following Jesus and Christian identity
}

Vera Ivanise Bombonatto

\section{Resumo}

Em meio às transformações do momento atual, torna-se necessário repensar a identidade cristã a partir da realidade e à luz do evento central da fé cristã: Jesus de Nazaré. Ser cristão não é simplesmente aceitar uma doutrina e ser fiel a determinadas normas, sem dúvida, importantes, mas é seguir uma pessoa que nos atrai a si e conquista o nosso coração: Jesus de Nazaré. Ser cristão é responder ao chamado de Jesus e colocar-se a caminho, seguindo seus passos, movido pela força do seu Espírito. É entrar na dinâmica processual do discipulado e fazer a experiência de estar com Jesus e ser por ele enviados em missão. É no processo de discipulado que a identidade cristã vai sendo construída. Estabelece-se assim entre seguimento e identidade cristã uma relação íntima e profunda: o seguimento se transforma em caminho insubstituível para, simultaneamente, conhecer Jesus e construir a identidade cristã.

Palavras-chave: Seguimento de Jesus. Identidade cristã. Cristologia. História da salvação. Histórica de seguimento.

\section{Abstract}

In the midst of current moment transformations, it is necessary to rethink the Christian identity from the reality and in the light of central event of Christian faith: Jesus of Nazareth. Being a Christian isn't simply accept a doctrine and be faithful to certain rules, undoubtedly, important, but it is to follow a person who draws us to himself and win our hearth: Jesus of Nazareth. Being a Christian is to respond to the call of God and to 
set out on the voyage, following his footsteps by the power of his Spirit. It is to enter a procedural dynamic of discipleship and to do an experience of being with Jesus and sent on mission by him. Christian identity is built through the process of discipleship. It is thus established between following and Christian identity an intimate and profound relationship: The following becomes an irreplaceable way to, simultaneously, know Jesus and built a Christian identity.

Keywords: Following Jesus. Christian identity. Christology. History of salvation. Following historical.

\section{Introdução}

As profundas e rápidas transformações, que estão ocorrendo, em todos os campos do saber e em todas as esferas da atividade humana, e os consequentes desafios que emergem deste contexto, trazem consigo um imperativo: a necessidade de repensar a identidade cristã a partir da realidade e à luz do seu evento central da fé cristã: Jesus de Nazaré.

Esta complexa e exigente tarefa de repensar a identidade cristã num mundo globalizado, pósmoderno e em constante transformação, recoloca, no centro da reflexão teológica, a questão da cristologia e do seguimento de Jesus. Quem é Jesus para o ser humano pósmoderno, inserido num mundo globalizado e na cultura da comunicação? Como ser discípulos missionários, dando continuidade à prática de Jesus, por meio do seu seguimento? O que significa ser cristão hoje, em nossa sociedade plural e em transformação?

A busca de respostas, coerentes e satisfatórias, a estas questões existenciais está inquietando e mobilizando as pessoas de boa vontade, sensíveis aos sinais dos tempos, no esforço comum para encontrar soluções multidisciplinares adequadas, que deem sentido e sustentabilidade à vida humana.

Neste contexto, esta reflexão se concentra nos seguintes pontos: (1) a abrangência do conceito de seguimento de Jesus; (2) o seguimento como melhor forma de explicitar a identidade cristã; (3) a história da salvação como história de seguimento; (4) o Mestre Jesus de Nazaré; (5) a história do cristianismo como história de seguimento. 


\section{Abrangência do conceito de seguimento de Jesus}

Uma importante constatação atual é, sem dúvida, a da emergência de uma nova perspectiva em relação ao seguimento de Jesus.

É comum considerar o seguimento de Jesus, expressão da relação experiencial do cristão com Jesus Cristo, como um conceito pertencente ao âmbito da espiritualidade e, consequentemente, como parte integrante do tratado de Teologia Espiritual. Entretanto, recentemente, emergiu uma nova perspectiva em relação ao seguimento de Jesus, o qual passou a ser considerado também e preferencialmente como categoria cristológica, e, por conseguinte, como objeto da cristologia, ampliando assim sua abrangência e sua incidência teológica, superando a visão redutiva, fragmentada e estática e evitando o perigo do fundamentalismo, do espiritualismo e do devocionismo.

O esforço dos teólogos para resgatar o conceito de seguimento não constitui um fato isolado. Suas raízes devem ser buscadas no horizonte do processo histórico de compreensão da vida, missão e destino de Jesus de Nazaré e da preocupação que polarizou a atenção dos teólogos nestes últimos tempos: a volta ao Jesus histórico. ${ }^{1}$

A revalorização da história de Jesus constitui o fato gerador do processo de reapropriação do conceito de seguimento. Porém, não consta que a questão do seguimento de Jesus estivesse explicitamente presente nos fatos, nas preocupações e nos objetivos que originaram o movimento de volta ao Jesus histórico. Entretanto, numa avaliação retrospectiva, podemos afirmar que existe, sem dúvida, uma relação entre o esforço de redescoberta da dimensão histórica de Jesus e o resgate da categoria de seguimento, que só num segundo momento foi percebida de forma sensível. ${ }^{2}$

O debate sobre o Jesus histórico e o Cristo da fé não é um simples problema da ciência histórica, mas uma questão teológica significativa. A pergunta pelo Jesus histórico não é uma questão do passado, mas pertence à essência do cristianismo, que não se define como uma doutrina, mas como o seguimento de uma pessoa.

\footnotetext{
${ }^{1}$ Martín Hengel observa que, num primeiro momento, a pesquisa sobre os evangelhos e sobre o Jesus histórico deixou em segundo plano a questão do seguimento. HENGEL, M. Seguimiento y carisma: la radicalidad de la llamada de Jesús. Santander: Sal Terrea, 1981, p. 10.

${ }^{2}$ HENGEL, M. Seguimiento y carisma, p. 10.
} 


\section{A relação entre seguimento de Jesus e identidade cristã}

A partir desta visão, é possível refletir sobre a relação entre seguimento e a identidade cristã. Delinear o rosto de Jesus de Nazaré - certificar-se da veracidade de suas palavras, da pretensão messiânica de seus gestos - é uma questão significativa, dela derivam consequências vitais. Se Jesus de Nazaré é verdadeiramente o Verbo eterno, o Messias anunciado pelos profetas que, na plenitude dos tempos assumiu a natureza humana, a única alternativa é segui-lo, pois nele se encontra a vida e a salvação. ${ }^{3}$

Ser cristão não é simplesmente aceitar uma doutrina e ser fiel a determinadas normas, sem dúvida, importantes, mas é seguir uma pessoa que nos atrai a si e conquista o nosso coração: Jesus de Nazaré. É responder ao chamado de Jesus e colocar-se a caminho, seguindo seus passos, movido pela força do seu Espírito. É entrar na dinâmica processual do discipulado e fazer a experiência de estar com Jesus e ser por ele enviados em missão.

Por conseguinte, o seguimento de Jesus é a melhor forma de explicitar a identidade cristã. O próprio Jesus ensinou que no seu seguimento consiste a identidade cristã de quem aderiu à pessoa dele na História e de quem crer nele depois da ressurreição. ${ }^{4}$ É no processo de seguimento que vai sendo construída a identidade cristã. Estabelece-se, assim, entre seguimento de Jesus e a identidade cristã uma relação íntima e profunda. $O$ seguimento se transforma em caminho insubstituível para, simultaneamente, reconhecer Jesus e construir a identidade cristã.

Realizar a identidade cristã a partir do seguimento é viver em constante tensão entre reproduzir e atualizar. O seguidor deve reproduzir a estrutura fundamental da vida de Jesus: encarnação, missão, cruz e ressurreição e, ao mesmo tempo, atualizá-la, inspirado e animado pelo Espírito de Jesus e de acordo com as exigências do contexto em que vive. A identidade cristã deve ser constantemente repensada e reconstruída à luz do Espírito que conduz a história.

A identidade cristã tem duas dimensões significativas expressas nestes dois verbos: recordar que Deus se manifestou em Jesus. Essa memória perene nos leva a outras realidades que não podem ser esquecidas: a relação de Jesus com o Pai, o projeto do Reino de Deus, a prática de Jesus e sua relação com os

\footnotetext{
${ }^{3}$ Cf. CIOLA, N. Introdução à cristologia. São Paulo: Loyola, 1992, p. 7.

${ }^{4}$ Cf. SOBRINO, J. "Identidade cristã". In: FLORISTÁN SAMANES, C.; TAMAYO-ACOSTA, J. J. (Orgs.). Dicionário de conceitos fundamentais do cristianismo. São Paulo: Paulus, 1999, p. 343.
} 
pobres $;{ }^{5}$ caminhar: o Deus de Jesus é um Deus do caminho, a fé cristã nesse Deus é um caminhar humildemente com Deus na história, praticando a justiça e amando com ternura. ${ }^{6}$

Conceber a identidade cristã como realidade dinâmica que se constroi no processo de seguimento contribui, de forma expressiva, para subtraíla da abstração e da alienação e reforça seu caráter cristocêntrico e, consequentemente, seu compromisso com o prosseguimento da prática de Jesus, mediante a construção do Reino anunciado por ele e a luta para destruir as forças do anti-reino.

O seguimento de Jesus passa a ser uma categoria cristológica e, como tal, introduz na estrutura da identidade cristã uma força dinamizadora capaz de subtraí-la de toda a rigidez e estagnação. A identidade cristã é alimentada e vivificada constantemente pela força da palavra de Jesus que chama: "Vem e segue-me" (cf. Mt 4,18-22) e envia em missão: "Ide por todo mundo e pregai o Evangelho a toda a criatura" (Mt 28,19).

Ser cristão é entrar no movimento da vida de Jesus que armou sua tenda entre os pobres e excluídos deste mundo, anunciando-lhes a boanova do Reino, que passa pela cruz, mas não termina nela e sim na ressurreição.

\section{A história da salvação como história de seguimento}

O seguimento de Jesus é uma categoria fundamental em toda a história da salvação, porque engloba todos os elementos da resposta humana à intervenção de Deus na história da pessoa, por meio de Jesus. ${ }^{7}$

Deus chama constantemente e de diversos modos. O primeiro chamado que Deus dirige às suas criaturas é o chamado à existência. $\mathrm{O}$ ser humano, interlocutor de Deus, traz dentro de si a marca indelével do peregrinar; é um eterno caminhante em direção a si mesmo, ao próximo e ao transcendente.

\subsection{Primeira Aliança}

Javé chama Abraão para seguilo rumo a um país distante e desconhecido (cf. Gn 12,1), escolhe Israel para ser seu povo (cf. Nm 23,9) e seguir os seus

\footnotetext{
${ }^{5}$ Cf. SOBRINO, J. A fé em Jesus Cristo: ensaio a partir das vítimas. Petrópolis: Vozes, 2000, pp. 489-495.

${ }^{6}$ Cf. SOBRINO, J. A fé em Jesus Cristo, pp. 496-500.

${ }^{7}$ Cf. MAZZEO, M. La sequela di Cristo nel libro dell 'Apocalisse. Milano: Paoline, 1997, pp. 70 e 92.
} 
caminhos (cf. Dt 13,5); os patriarcas e os profetas têm a missão de conduzir o povo pelos caminhos de Javé. De modo geral, a expressão "seguir Javé" (cf. Dt 1,36; 1Rs 14,8;18,21; 2Rs 23,3; Jr 2,2) significa inclinação, dependência, obediência, reconhecimento da soberania, aceitação dos mandamentos e preconceitos.

Entretanto, no desenrolar da história de Israel, essa expressão adquire matizes variados e se torna mais concreta quando se trata do seguimento não dos deuses ou de Javé e sim do enviado de Javé, do profeta, de onde nasce a relação mestre-discípulo. ${ }^{8}$

João Batista, o precursor, exorta o povo a preparar os caminhos do Senhor e a endireitar as veredas, como está escrito no livro dos oráculos do profeta Isaías (cf. Lc 3,4). O AntigoTestamento constitui, assim, o ambiente natural e a pré-história na ação evangélica do seguimento. ${ }^{9}$

\subsection{Nova e Eterna Aliança}

O Novo Testamento é a plena realização, na pessoa de Jesus, dos desígnios divinos, preanunciados no AntigoTestamento. Jesus é a personalização do chamado de Deus que se fez carne e armou sua tenda entre nós (cf. Jo 1,14). Ele revela o Pai e é o apelo escatológico que propõe à liberdade humana uma mudança radical. Jesus, como enviado de Deus e Filho unigênito, está associado ao Pai no chamado; como homem responde no mundo e pelo mundo diante do Pai.

Cada evangelista, de acordo com a realidade concreta de sua comunidade e o objetivo específico do seu evangelho, salienta determinados aspectos não só do seguimento e do discipulado, mas do próprio rosto de Jesus de Nazaré. A tradição neotestamentária no que se refere à experiência do seguimento e do discipulado, é extremamente rica e plural.

Os traços característicos do seguimento encontram-se, particularmente, nas narrativas da vocação dos primeiros discípulos e nos ditos (logias) de Jesus a este respeito. As narrativas das vocações são contextualizadas e trazem informações acerca dos nomes e da profissão das pessoas que encontraram Jesus; os ditos (logias), em geral, são anônimos e generalizados. A atenção é centrada na pessoa de Jesus e na sua tomada de posição.

${ }^{8}$ Cf. BLANCO, S. “Seguimento”. In: RODRÍGUEZ, A. A.; CASAS, J. C. (Orgs.) Dicionário teológico da vida consagrada. São Paulo: Paulus, 1997, p. 1010.

${ }^{9}$ Cf. MAZZEO, M. La sequela di Cristo nel libro dell'Apocalisse, p. 82. 
De acordo com o testemunho dos evangelistas, pode-se afirmar que a expressão "seguir" ou "ir atrás de" tem, pelo menos, três significados diferentes:

- o primeiro, seguir fisicamente Jesus ou outra pessoa;

- o segundo, seguir fisicamente unido à vinculação espiritual à pessoa de Jesus: o seguidor acompanha permanentemente Jesus, adere à sua causa e participa de seu destino;

- terceiro, seguir simbólico: superada a fase originária da itinerância de Jesus e de seus discípulos, o termo adquire uma densidade própria e um valor simbólico e converte-se em expressão da vida cristã. ${ }^{10}$

Podemos então distinguir dois momentos importantes e intrelaçados, tendo como linha divisória a páscoa de Jesus.

\subsection{Seguimento pré-pascal}

Antes da Páscoa, o seguimento está visivelmente ligado ao Mestre Jesus de Nazaré e se apresenta como uma realidade histórica irrepetível. Jesus chama algumas pessoas do meio de seu povo para partilharem a vida com ele e colaborarem com a sua obra messiânica.

A tradição evangélica identifica diferentes tipos de seguidores de Jesus:

- pessoas que, em momentos esporádicos, sem mudar de vida, seguem fisicamente Jesus em sua itinerância;

- pessoas que, depois do chamado explícito de Jesus, rompem com a situação anterior, adotam nova forma sociológica de vida e acompanham Jesus de modo permanente, apropriando-se de seu estilo de vida;

- pessoas que, somente em sentido figurado, podem ser chamadas de seguidoras. ${ }^{11}$

Pressupostos:

Jesus fala dos pressupostos para segui-lo, que não devem ser confundidos

${ }^{10}$ Cf .MAZZEO, M. La sequela di Cristo nel libro dell'Apocalisse, p. 72.

${ }^{11}$ Cf. BLANCO, S. "Seguimento", p. 1011. 
com pré-requisitos profissionais; são antes condições necessárias para estar a serviço do Reino de Deus.

- O primeiro pressuposto para quem quer seguir é a ruptura com os ligames familiares (Lc 14,26; Mt 10,37; Mc 1,20). Somente quem estiver disposto a renunciar a todos os laços terrenos é apto para se tornar colaborador do Messias. Jesus tem expressões duras a esse respeito. Elas revelam a singularidade de sua pessoa e de sua missão salvífica (cf. Lc 9,59). ${ }^{12}$

- O segundo pressuposto é expresso no binômio "carregar a cruz" e "seguir Jesus" (cf. Lc 14,27). Provavelmente, a morte na cruz introduzida pelos romanos na Palestina, na qual o condenado era obrigado a carregar o patibulum, isto é, a trave transversal, até o lugar da execução — originou a expressão "carregar a cruz". Nos últimos decênios, antes da destruição de Jerusalém, toda a tentativa de revolta de fundo messiânico poderia ser sufocada com a crucificação dos culpados. É de se supor que Jesus, ao usar a expressão "carregar a cruz" como condição para segui-lo, teria levado em conta essa possibilidade. Na tradição sinótica, a expressão "seguir" é interpretada como comunhão de vida e está sempre relacionada com a imagem de "carregar a cruz". ${ }^{13}$

- O terceiro pressuposto é a renúncia às propriedades. No evangelho de Marcos, a resposta ao convite de Jesus inclui sempre o abandono do próprio ambiente (cf. Mc 1,18.20 par.); o acompanhar Jesus, indo ao encontro de uma nova existência, totalmente incerta; e o partilhar a situação existencial do Filho de Deus (cf. Mt 8,20). ${ }^{14}$

\subsection{Seguimento pós-pascal}

A morte de Jesus rompe os laços terrenos e sensíveis que uniam os seguidores ao seu Mestre e Senhor. Ela faz nascer uma íntima familiaridade com o Cristo ressuscitado e com seu Espírito. Os seus seguidores tinham consciência de que continuavam pertencendo a ele e se davam conta de que

\footnotetext{
${ }^{12}$ Cf. SCHULZ, A. Discípulos do Senhor. São Paulo: Paulus, 1969, pp. 47-49.

${ }^{13}$ Cf. SCHULZ, A. Discípulos do Senhor, pp. 50-56.

${ }^{14}$ Cf. SCHULZ, A. Discipulos do Senhor, pp. 56-59.
} 
formavam sua comunidade, o novo e verdadeiro povo escolhido de Israel. À luz da ressurreição, as palavras de Jesus adquirem novo significado e o conceito de seguimento passa por uma profunda transformação, sem perder o seu significado original.

Os evangelhos sinóticos - escritos na perspectiva da ressurreição apresentam uma ambivalência. De um lado, narram o desenvolvimento histórico das atividades de Jesus; de outro, transformam o significado das palavras seguir e discípulo, pronunciadas por Jesus, com o objetivo de tornálas normativas e correspondentes à realidade concreta também daqueles cristãos aos quais já não é mais possível seguir o mestre Jesus nas estradas da Palestina. ${ }^{15}$

O evangelista Marcos salienta, de modo particular, a participação no destino do crucificado, reflexo, sem dúvida, da situação hostil em que viviam as comunidades siro-galileias; Mateus enfatiza a dimensão escatológica, o novo povo de Deus, e ética, a nova justiça; Lucas realça a participação no caminho de Jesus rumo a Jerusalém; João faz uma fusão entre seguimento prépascal e fé pós-pascal, a realidade do seguimento se transforma em realidade de fé: "Eu sou a luz do mundo e quem me segue não andará nas trevas, mas terá a luz da vida" $\left(\mathrm{Jo}_{0} 8,12\right){ }^{16}$

O seguimento do Jesus histórico é apresentado como uma forma paradigmática de relação-comunhão com Jesus. Ao recordar o chamado de Jesus e a resposta radical de seus seguidores, a comunidade pós-pascal confessa sua fé no Senhor ressuscitado e exaltado, presente no meio dela. Seguir se transforma em um termo teológico que caracteriza o ser cristão e assume um significado que ultrapassa a primitiva acepção concreta; é a resposta de fé ao apelo de Jesus ressuscitado para dar continuidade à sua causa. ${ }^{17}$

Após a ressurreição de Jesus, as comunidades primitivas conservaram suas palavras e seus gestos, que chegaram a nós codificados nos escritos do Novo Testamento.

\footnotetext{
${ }^{15}$ Cf. SCHULZ, A. Discípulos do Senhor, pp. 65-69.

${ }^{16}$ Cf. FERNÁNDEZ, B. Seguir a Jesús, el Cristo. Madrid: Publicaciones Claretianas, 1998, pp. 145-146; VIDAL, S. "El seguimiento de Jesús e nel Nuevo Testamento. Visión general". In: GARCÍA-LOMAS, J. M.; GARCÍA-MURGA, J. R. (Eds.). El seguimiento de Cristo. Madrid: Promoción Popular Cristiana, 1997, pp. 21-22.

${ }^{17}$ Cf. MAZZEO, M. La sequela di Cristo nel libro dell'Apocalisse, pp. 88-92.
} 
De acordo com os Evangelhos sinóticos, em relação aos destinatários, o chamado de Jesus para viver em comunhão com ele evolui progressivamente, passando por três momentos distintos, que podem-se chamar de processo de universalização do seguimento. Jesus dirige seu convite: a algumas pessoas escolhidas, à multidão e a todos indistintamente.

Depois do batismo, ao iniciar sua vida pública, Jesus dirige o seu convite a algumas pessoas escolhidas, que vivem em realidades diferentes e exercem as mais variadas atividades. Simão Pedro e seu irmão André eram pescadores de Betsaida (cf. Jo 1,44); Mateus era cobrador de impostos em Cafarnaum (cf. Mt 9,9). "Caminhando à beira do mar da Galiléia, Jesus viu Simão e seu irmão André, lançando as redes ao mar, pois eram pescadores. Então disse-lhes: 'Segui-me, e eu vos farei pescadores de homens"' (Mc 1,16).

Os evangelhos sinóticos se referem ao convite de Jesus dirigido a doze homens para viverem em comunhão mais íntima com ele. O número doze tem um significado simbólico: manifesta a indissolúvel conexão entre a vida de Jesus e o povo formando pelas doze tribos. ${ }^{18}$

Como missionário itinerante, percebendo a presença não só de um pequeno grupo de escolhidos, mas de muitos que o acompanhavam, Jesus estende o seu convite às multidões: "Chamando a multidão, juntamente com os seus discípulos, disse-lhes: 'Se alguém quiser vir após mim, negue-se a si mesmo, tome a sua cruz e siga-me'” (Mc 8,34).

O chamado de Jesus não se limitou aos "doze", isto é, aos membros fiéis do povo de Israel. Jesus chamou também os pecadores, os publicanos, as pessoas excluídas e marginalizadas.

Durante sua vida pública, Jesus dirige o seu convite a todos indistintamente e universaliza o seu chamado. "Dizia ele a todos: 'Se alguém quer vir após mim, renuncie a si mesmo, tome a sua cruz cada dia e siga-me"” (Lc. 9,23).

Ninguém ficou excluído da possibilidade de seguir Jesus. Ele chamou jovens (Mc 10,20), pobres e pecadores (Mt 4,18-22), doentes e "possuídos pelo demônio" (Mt 8,16; Mc 5,2-20) e também mulheres (Mt 9,20; Lc 7,36-50; Lc 15,1-31; Jo 8, 1-11). Neste processo de universalização, percebese um crescendo que inicia com a comunidade dos doze e chega à abrangência total: todos são chamados ao seguimento. A partir do grupo dos doze, Jesus universaliza seu chamado.

${ }^{18}$ Cf. SCHULZ, A. Discipulos do Senhor, p. 4144. 
O chamado de Jesus ao seu seguimento é universal, mas cada um responde, livremente, segundo a graça que lhe é dada e os dons recebidos. Temos assim, na família de Deus, as diferentes vocações.

\section{O mestre Jesus de Nazaré}

Ao comparar Jesus com os mestres do seu tempo, percebem-se algumas semelhanças exteriores. Entre elas podemos elencar as seguintes:

Jesus é reconhecido por seus contemporâneos como mestre ${ }^{19}$ e como chefe de uma escola que, inicialmente, possui doze discípulos que convivem com ele. Os discípulos seguem Jesus em suas peregrinações (cf. Mc 6,1; Mt 8,23; Lc 22,9) e desempenham os serviços que no tempo dos rabinos eram considerados decisivos para o futuro de sua profissão. Os discípulos recebem as instruções especiais na casa do mestre (cf. Mc 7,17; 9,28-33; 10,10; Mt 17,25).

$O$ método de ensino usado envolve perguntas dos discípulos e também instruções em forma de palestras. ${ }^{20}$ Jesus recorre frequentemente a parábolas, meio didático bastante conhecido em seu tempo; usa metáforas empregadas pelos doutores da Lei; rebate as objeções de seus opositores com citações do Primeiro Testamento. A atividade de Jesus desenvolve-se sobretudo na sinagoga e no Templo, onde também os rabinos costumavam instruir o povo.

Apesar desses pontos comuns com o sistema rabínico, existem diferenças essenciais motivadas fundamentalmente pela consciência que Jesus tinha de sua missão salvífica. O seguimento exterior é sinal visível da íntima união com Jesus e da participação em sua vida e missão. O novo modo de chamar inaugurado por Jesus tem características particulares. Lembramos, a seguir, as mais significativas.

\footnotetext{
${ }^{19}$ Os rabinos contemporâneos a Jesus o reconhecem como mestre (cf. Mc 12,32; Mt 22,36; Lc 10,25; Mt 12,38; Lc 11,45; 20,39) e lhe pedem conselho (cf. 12,28-34), envolvendo-o em disputas. O pretexto para a disputa é dado por algum ato de Jesus, ou de seus discípulos, que esteja em contraste com as normas fixadas pelo sistema rabínico. Cf. BLANK, J. "Seguimento". In: EICHER, P. (Org.). Dicionario de conceitos fundamentais da teologia. São Paulo: Paulus, 1993, p. 820; SCHULZ, A. Discípulos do Senhor, p. 26.

${ }^{20} \mathrm{O}$ fato de Jesus se retirar da multidão em companhia dos doze e dedicar-se à instrução dos mesmos é uma prova de que ele empregava também o método das palestras. Esse aspecto da vida de Jesus é destacado principalmente no Evangelho de Marcos (8,27-10,52). Cf. SCHULZ, A. Discípulos do Senhor, p. 26.
} 
Jesus toma a iniciativa e escolhe os seus discípulos: Na escola de Jesus, não são os discípulos que escolhem o mestre com base em critérios préestabelecidos, mas é Jesus quem toma a iniciativa e, agindo com autoridade profética, escolhe seus discípulos. Tudo tem início com um encontro e uma palavra autorizada, eficaz e criativa de Jesus: Segue-me. Essa palavra expressa sua vontade eletiva em relação à pessoa chamada. Por meio de Jesus, Deus intervém na vida das pessoas. É Deus quem procura o ser humano nas coordenadas do tempo e da história. ${ }^{21}$

Neste sentido, Jesus retoma a concepção profética de seguimento, expressa particularmente no caso de Elias (1Rs 19,19-21), no qual não é o profeta que chama, mas Deus, representado no gesto simbólico de jogar o manto. ${ }^{22}$

O centro do seguimento não é a Lei, mas Jesus e a fé na sua pessoa como o Filho de Deus e enviado do Pai, na força do Espírito. A fé em Jesus está na origem e no caminho de seguimento, que acontece em meio a luzes e sombras. Todo o relacionamento recíproco entre Jesus e seus discípulos se desenvolve no horizonte da fé nele como o Messias.

A autoridade de Jesus. Como mestre, a autoridade de Jesus não está no saber que possui, nem no fato de ser perito na interpretação da Lei, mas na sua própria pessoa, o enviado do Pai. Entretanto, os discípulos não se colocam a serviço de Jesus, como no caso de Elias, em que Eliseu se colocou a seu serviço. Os discípulos seguem Jesus, que está junto com eles como alguém que serve (cf. Lc 22,27).

Comunhão vital com Jesus: A relação mestre-discípulo não se limita ao fato de ensinar e aprender uma doutrina, mas é uma comunhão vital com Jesus e se traduz na obediência incondicional à sua palavra. Os seguidores de Jesus participam de sua vida, de suas atividades, particularmente do anúncio do Reino. Porém, eles dependem plenamente de Jesus e agem em comunhão com ele. Sem a relação-comunhão vital com Jesus, a pregação da boa-nova do Reino perde toda sua força de transformação.

O seguimento é permanente: O seguimento de Jesus não tem um período de tempo limitado, como no caso dos rabinos: até que o discípulo se torne

\footnotetext{
${ }^{21}$ Cf. FERNANDEZ, B. Seguir a Jesús, el Cristo, pp. 126-127.

${ }^{22}$ Cf. GNILKA, J. Jesus de Nazaré: mensagem e história. Petrópolis: Vozes, 2000, p. 156.
} 
experto na interpretação da Lei; não é o início de uma carreira, mas uma entrega total e permanente. Exige uma resposta pessoal dada no tempo, mas que tem uma dimensão de eternidade, da eternidade de Deus, para o qual o passado, o presente e o futuro são um único momento.

Objetivo do seguimento: $\mathrm{O}$ discípulo de Jesus não tem como objetivo tornar-se intérprete da Lei por meio de um estudo sistemático, mas é chamado a deixar-se plasmar por ele, seguindo seus passos. Participa das preocupações cotidianas do mestre e usufrui de sua intimidade. Recebe os conteúdos para a pregação de forma não sistemática.

Se, de um lado, Jesus ao chamar não propõe um programa de vida, de outro, deixa claro que o seu convite tem uma finalidade precisa. $\mathrm{O}$ seguidor deve assemelhar-se a Jesus de Nazaré, reproduzindo sua vida histórica, exercendo a missão como ele exerceu: sem levar pão, nem alforje, nem dinheiro no cinto (Mc 6,8); e participando do seu destino: Vós sois os que permanecestes comigo nas minhas provações (Lc 22,28); assumir sua causa e dispor-se a ser enviado em missão por Jesus e em lugar dele: eu vos farei pescadores de homens (Mc 1,17).

\subsection{Chamados a estar com Jesus}

O seguimento tem uma especificidade própria e inconfundível, que se expressa na relação-comunicação pessoal com Jesus. Ao chamar para seguilo, Jesus de Nazaré não dita normas a serem observadas rigorosamente, não traça antecipadamente projetos a serem realizados, não faz inúmeras e tentadoras promessas a serem cumpridas. Faz questão de deixar muito claro que o seguimento é, acima de tudo, uma relação profunda e pessoal com ele, que implica numa ruptura com o passado e no misterioso começo de uma existência radicalmente nova.

Seguir Jesus supõe dúplice relação: de proximidade e de movimento: estar com Jesus (cf. Mc 3,14); manter-se ao seu lado nas provações (cf. Lc 22,28); ter os mesmos sentimentos e atitudes de Jesus (cf. Fl 2,5); tornar-se filho no Filho (cf. Rm 8,29); ter os olhos fixos em Jesus (Hb 12,12).

$\mathrm{O}$ convite de Jesus tem uma finalidade precisa. O seguidor deve:

- assemelhar-se a ele reproduzindo sua vida histórica, exercendo a missão como ele exerceu: "sem levar pão, nem alforje, nem dinheiro no cinto" (cf. Mc 6,8); e 
- participar do seu destino;

- assumir a causa de Jesus e dispor-se a ser enviado em missão por ele e em lugar dele.

Jesus chamou seus discípulos para estarem com ele (Mc. 3,14) e para que, estando com ele, assimilassem os seus ensinamentos e vivessem como ele viveu: em constante relação-comunhão com o Pai e a serviço do Reino. Encontrar-se com Jesus implica entrar na intimidade com ele, converter-se e comprometer-se com o projeto de vida do Pai, em todas as suas dimensões: pessoal, comunitária, social, política e ecológica.

\subsection{Enviados a testemunhar e a anunciar o reino da vida}

Ao chamar para segui-lo, Jesus convoca e envia a anunciar o Evangelho a todas as nações (cf. Mt 28,19; Lc 24, 46-48). O discípulo é missionário, pois Jesus o torna participante de sua missão ao mesmo tempo em que o vincula a si como amigo e irmão. Deste modo, como Jesus é testemunha do mistério do Pai, assim os discípulos são testemunhas da morte e ressurreição do Senhor até que ele venha. "Cumprir este encargo não é uma tarefa opcional, mas parte integrante da identidade cristã, porque é a extensão testemunhal da mesma vocação". ${ }^{23}$

Existe, portanto, uma profunda e íntima relação entre chamado e envio, entre assemelhar-se a Jesus e ser enviado em missão. Seguimento é colocar-se, como Jesus, a serviço do Reino, anunciando sua proximidade e realizando os sinais concretos de sua presença; é reproduzir a mesma realidade de Deus que em Jesus de Nazaré se manifestou como salvação para o povo.

A resposta ao chamado de Jesus faz a pessoa entrar na dinâmica do Bom Samaritano (cf. Lc 10,29-37), tornando-nos próximos, especialmente dos que sofrem. É um sim que compromete radicalmente o discípulo e o faz tornar-se, com Jesus e em Jesus, Caminho, Verdade e Vida da humanidade (cf. Jo 14,6). ${ }^{24}$

${ }^{23}$ CELAM. Documento de Aparecida. Texto conclusivo da V Conferência Geral do Episcopado Latino-Americano e do Caribe. Brasília - São Paulo: Edições CNBB - Paulus - Paulinas, 2007, n. 144.

${ }^{24}$ Cf. CELAM. Documento de Aparecida, nn. 135-136. 


\section{A história do cristianismo é uma história de seguimento}

$\mathrm{Na}$ história da Igreja e da teologia, o tema do seguimento de Jesus tem uma longa, complexa e conturbada trajetória, marcada por inúmeras situações paradoxais. De um lado, o imperativo de Jesus vem e segue-me (cf. Mt 4,19; Mc 1,17; Lc 5,10; Jo 1,43) permanece como o fundamento inabalável e o movente propulsor dos mais variados movimentos de renovação da vida cristã; de outro, os teólogos ficam perplexos quando se defrontam com o mistério do chamado divino e da resposta humana, e se confundem ao tentarem sistematizar o seu conteúdo. $^{25}$

A vida, as palavras e os gestos de Jesus exerceram e continuam exercendo um fascínio irresistível na consciência e no coração do ser humano. O cristianismo não se define como uma religião, mas como o seguimento de uma pessoa: Jesus Cristo. Em momentos particularmente kairóticos, o chamado ao seguimento de Jesus torna-se o único princípio inspirador e normativo de pessoas carismáticas e proféticas como Inácio de Antioquia, Francisco de Assis, Inácio de Loyola, Tereza d'Avila, Charles de Foucauld, Tiago Alberione e tantos outros. ${ }^{26}$

Apesar disso, nem sempre o tema do seguimento de Jesus ocupou o centro dos interesses da exegese bíblica, da reflexão teológica e da história do cristianismo. Talvez aqui também se evidencie um aspecto da ruptura, tantas vezes lamentada, entre experiência de fé vivida no cotidiano e as categorias epistemológicas e hermenêuticas do fazer teológico.

Reconstituir a história do seguimento de Jesus em toda a sua amplitude e complexidade, torna-se uma tarefa quase impossível. Não é nossa intenção traçar uma história exaustiva da evolução dos conceitos de seguimento na tradição cristã e de suas múltiplas formas de expressão. Nem pretendemos analisar as questões exegéticas e teológicas que envolvem esses conceitos e suas implicações para a vida cristã.

${ }^{25}$ Cf. DI PINTO, L."'Seguire Gesù' secondo i vangeli sinottici”. In: ASSOCIAZIONE BIBLICA ITALIANA. Fondamenti biblici della teologia morale. Bréscia: Paideia, 1973, pp. 189-190. BOMBONATTO, V. I. Seguimento de Jesus: Uma abordagem segundo a cristologia de Jon Sobrino. São Paulo: Paulinas, 2002.

${ }^{26}$ Cf. DI PINTO, L.“'Seguire Gesù' secondo i vangeli sinottici”, p. 190; SOBRINO, J. Ressurreição da verdadeira Igreja: os pobres, lugar teológico da eclesiologia. São Paulo: Loyola, 1982, p. 32.

${ }^{27}$ Cf. BOMBONATTO, V. I. Seguimento de Jesus: Uma abordagem segundo a cristologia de Jon Sobrino. São Paulo: Paulinas, 2002. 
Nosso objetivo é apenas evidenciar que o seguimento de Jesus é parte integrante e essencial da tradição cristã e constitui um eixo central do cristianismo, a ponto de podermos afirmar que a história do cristianismo é uma história de seguimento.

O seguimento atravessa a história do cristianismo como modo de expressar a experiência cristã. Cada momento histórico, percebendo de modo singular os desafios da realidade e sob a ação do Espírito de Jesus e do Pai, interpreta de forma diferente o chamado ao seguimento e elabora de modo singular a própria resposta.

Ao longo da história, o conceito de seguimento, característico dos evangelhos, se cruza com o conceito de imitação, encontrado, prevalentemente, nos escritos paulinos. A imensa gama de matizes do significado desses termos e a pertinência e a relevância de cada um tornam quase impossível uma nítida separação.

As coordenadas histórico-culturais, a cristologia, a eclesiologia e as diferentes preocupações pastorais projetam luzes, ora sobre o conceito de seguimento, deixando na sombra o conceito de imitação, ora sobre o conceito de imitação, deixando na penumbra o conceito de seguimento.

\subsection{Martírio: expressão de seguimento}

Nos primeiros séculos do cristianismo, marcados pela perseguição violenta, o martírio era considerado a mais autêntica e perfeita expressão de seguimento e imitação do Mestre da Galileia, a mais qualificada profissão de fé e a mais radical profecia evangélica numa sociedade corrupta e idolátrica. Cristo mártir, presente na consciência dos cristãos como modelo a ser imitado, dava força para suportar os sofrimentos.

Os dois conceitos de seguimento e de imitação guardavam uma relativa distinção entre si e uma total referência à pessoa de Jesus Cristo. Imitar o exemplo do mártir Jesus de Nazaré era uma decorrência da fidelidade no seguimento radical, a ponto de entregar a própria vida.

\subsection{Vida monástica: radicalidade do seguimento}

Cessadas as perseguições, muitos cristãos sentiram falta da tensão escatológica do martírio e da fidelidade radical à pessoa de Jesus. Surge a necessidade de buscar formas novas para expressar a radicalidade do 
seguimento de Jesus e da imitação de sua paixão e morte. Nasce a vida monástica, uma espécie de martírio incruento. Na continuidade do martírio, a vida monástica é um chamado permanente à condição escatológica do cristão, que devia viver neste mundo consciente de sua transitoriedade, sem estabelecer aqui morada permanente.

Como o martírio, também a vida monástica se fundamenta num apaixonado cristocentrismo. A preocupação maior é a busca de formas de viver radicalmente a proposta de Jesus à imitação dos apóstolos. Como os apóstolos, eles deixam tudo para seguir Jesus, viver em comunidades, colocar os bens em comum e exercer a caridade fraterna.

\subsection{Santo Agostinho: seguir é imitar}

Santo Agostinho representa um marco na tradição cristã do seguimento e da imitação. Para ele, seguir é sinônimo de imitar; à medida que imitamos também seguimos.

Considerado um dos "doutores da imitação", santo Agostinho, em seu livro $A$ virgindade consagrada, faz uma pergunta que encerra uma afirmação: O que quer dizer seguir, senão imitar? Além de identificar os dois conceitos, ele subordina o seguimento à imitação: à medida que imitamos Jesus, também o seguimos.

Percebemos na afirmação de santo Agostinho que a imitação é o critério básico para avaliar o seguimento. A preocupação principal dos cristãos deve ser, por conseguinte, imitar Jesus, exemplo de todas as virtudes.

Essa subordinação da categoria cristológica de seguimento à de imitação, feita por santo Agostinho, exerceu uma influência ímpar na história desses dois conceitos. Seu pensamento gira ao redor de dois conceitos-chave: amar e imitar. A imitação é fruto do amor. Se o cristão ama a Cristo, procura também se assemelhar a ele, que é o perfeito modelo de todas as virtudes.

\subsection{A preocupação com a imitação de Cristo}

$\mathrm{Na}$ tradição cristã ocidental, durante o período em que predominou a teologia escolástica, desapareceu, quase por completo, o conceito de seguimento, dando lugar à preocupação pela imitação de Cristo.

A Idade Média, centralizando sua reflexão cristológica e sua vivência em torno da humanidade de Cristo, fez emergir fortemente o 
ideal da imitação, deixando em segundo plano o ideal do seguimento. Vários fatores contribuíram para reforçar o ideal da imitação. Entre eles, podemos citar: a reflexão dos teólogos sobre o conceito de imitação, a espiritualidade concebida como ascese e mística da imitação, a devotio moderna, particularmente a obra Imitação de Cristo e o enfoque dado à moral como disciplina prático-pastoral.

Algumas vozes proféticas clamaram pelo resgate da categoria de seguimento sob forma de contestação. Entre elas, destacamos Francisco de Assis, Domingos de Gusmão e Inácio de Loyola.

Reforçado pela teologia dos dois caminhos, o seguimento passou a ser considerado uma vocação especial na Igreja. Contra essa tendência reagiu a Reforma Protestante, sobretudo: Martinho Lutero, Sören Kierkegaard e Dietrich Bonhoeffer.

Atualmente, como vimos, diferentes fatores concorrem para a redescoberta do seguimento de Jesus como categoria cristológica e como melhor forma de explicitar a identidade cristã. Em suas homilias e catequeses, o papa Francisco se refere inúmeras vezes ao seguimento de Jesus relacionando-o com a identidade cristã.

José Maria Castilho, teólogo espanhol, afirma: “A teologia de Francisco é, sobretudo, a teologia do seguimento de Jesus. Uma teologia com a qual não estamos acostumados. Por isso, desconcerta a uns, irrita a outros, e a todos nós coloca perguntas que não sabemos responder. Perguntas que despachamos dizendo tranquilamente que este Papa 'não sabe Teologia', nem é o Papa de que a Igreja precisa. Será que não é a nossa Teologia que anda mais desorientada do que possamos imaginar?". ${ }^{27}$

\section{Considerações finais}

Na história da salvação, a comunicação do mistério de Deus não é apenas doutrinal e intelectual. Como toda a história de amor e de amizade é feita de gestos, símbolos, ações e palavras.

\footnotetext{
${ }^{27}$ CASTILLO, J. M. "La teología de Francisco es, ante todo la del seguimiento de Jesús". Religión Digital. Disponível em < http://www.periodistadigital.com/religion/opinion/2017/05/27/ jose-maria-castillo-la-teologia-de-francisco-es-ante-todo-la-del-seguimiento-de-jesus-iglesia-religion-dios-jesus-papa-obispo.shtml $>$. Traduzido por André Langer. Disponível em: $<$ http://www.ihu.unisinos.br/568110-a-teologia-do-papa-francisco-e-sobretudo-a-do-seguimento-de-jesus-artigo-de-jose-maria-castillo>. Acesso em 19 de fevereiro de 2018.
} 
No seguimento de Jesus e na resposta do discipulado, estão presentes três dimensões distintas e intrinsecamente relacionadas entre si: a memória, a vivência e o anúncio.

- A memória, que atualiza a prática de Jesus, suas atitudes em relação ao Pai e aos irmãos e seu mandato: "fazei isto em memória de mim". A fé cristã tem uma dimensão de memorial. Recordar, no sentido litúrgico, é tornar presente e visível o Cristo invisível, crucificado e glorioso. Crer é fazer memória dos gestos, das ações e palavra de Jesus. É inspirar-se em seus gestos e continuar sua opção radical em favor da vida onde quer que ela esteja ameaçada. Evocar o Jesus do Reino é provocar a continuidade de suas atitudes. Ele continua presente nos seus seguidores e atua entre eles e por meio deles. A celebração é uma forma de tornar presente as ações de Deus. ${ }^{28}$ A Igreja é "sinal e memorial vivo da permanente presença de Jesus". ${ }^{29}$

- A vivência, maneira concreta de ser fiel a Jesus na solidariedade para com os pobres, é reinventada constantemente em nossas vidas, pela força do Espírito que age em nós.

- O anúncio - Jesus venceu a morte - está vivo no meio de nós e nos envia a anunciar a boa nova do Reino, vivendo na esperança sempre reavivada, de que se pode viver gestos de ressurreição até que ela se realize plenamente.

Não existe, portanto, dicotomia entre seguimento de Jesus e identidade cristã, entre espiritualidade e seguimento de Jesus. A espiritualidade do seguimento de Jesus é profundamente pascal, pois nela está em jogo a dialética morte-vida, mas ela se fundamenta na vitória do Ressuscitado, que renova a cada dia a nossa esperança. ${ }^{30}$

\section{Referências bibliográficas}

BLANCO, S. "Seguimento”. In: RODRÍGUEZ, A. A.; CASAS, J. C. (Orgs.) Dicionário teológico da vida consagrada. São Paulo: Paulus, 1997, pp. 1010-1011.

${ }^{28}$ Cf. FERNANDEZ, B. Seguir a Jesús, el Cristo, pp. 53-60.

${ }^{29}$ Cf. JOÃO PAULO II. Pastores Dabo Vobis. Exortação Apostólica Pós-Sinodal sobre a formação dos Sacerdotes, São Paulo: Paulinas, 2009, n. 12.

${ }^{30}$ Cf. GUTIÉRREZ, G. Beber no próprio poço. Petrópolis: Vozes, 1987, p. 42. 
BLANK, J. "Seguimento". In: Eicher P. (Org.). Dicionário de conceitos fundamentais da teologia. São Paulo: Paulus, 1993, pp. 819-822.

BOMBONATTO, V. I. Seguimento de Jesus: Uma abordagem segundo a cristologia de Jon Sobrino. São Paulo: Paulinas, 2002.

CASTILLO, J. M. "La teología de Francisco es, ante todo la del seguimiento de Jesús". Religión Digital. Disponível em < http://www.periodistadigital. com/religion/opinion/2017/05/27/jose-maria-castillo-la-teologia-defrancisco-es-ante-todo-la-del-seguimiento-de-jesus-iglesia-religiondios-jesus-papa-obispo.shtml>. Traduzido por André Langer. Disponível em: <http:/www.ihu.unisinos.br/568110-a-teologia-do-papa-franciscoe-sobretudo-a-do-seguimento-de-jesus-artigo-de-jose-maria-castillo $>$. Acesso em 19 de fevereiro de 2018.

CELAM. Documento de Aparecida. Texto conclusivo da V Conferência Geral do Episcopado Latino-Americano e do Caribe. Brasília / São Paulo: Edições CNBB / Paulus / Paulinas, 2007.

CIOLA, N. Introdução à cristologia. São Paulo: Loyola, 1992.

DI PINTO, L.“'Seguire Gesù' secondo i vangeli sinottici”. In: ASSOCIAZIONE BIBLICA ITALIANA. Fondamenti biblici della teologia morale. Brescia: Paideia, 1973, pp. 187-251.

FERNÁNDEZ, B. Seguir a Jesús, el Cristo. Madrid: Publicaciones Claretianas, 1998.

GNILKA, J. Jesus de Nazaré: mensagem e história. Petrópolis: Vozes, 2000.

GUTIÉRREZ, G. Beber no próprio poço. Petrópolis: Vozes, 1987.

HENGEL, M. Seguimiento y carisma: la radicalidad de la llamada de Jesús. Santander: Sal Terrae, 1981.

JOÃO PAULO II. Pastores Dabo Vobis. Exortação Apostólica Pós-Sinodal sobre a formação dos Sacerdotes, São Paulo: Paulinas, 2009.

MAZZEO, M. La sequela di Cristo nel libro dell'Apocalisse. Milano: Paoline, 1997.

SCHULZ, A. Discípulos do Senhor. São Paulo: Paulus, 1969.

SOBRINO, J. A fé em Jesus Cristo: ensaio a partir das vítimas. Petrópolis: Vozes, 2000. 
SOBRINO, J. "Identidade cristã". In: FLORESTÁN SAMANES, C.; TAMAYO-ACOSTA, J. J.(Orgs.). Dicionário de Conceitos fundamentais do cristianismo. São Paulo: Paulus, 1999, pp. 342-354.

SOBRINO, J. Ressurreição da verdadeira Igreja: os pobres, lugar teológico da eclesiologia. São Paulo: Loyola, 1982.

VIDAL, S. "El seguimiento de Jesús e nel Nuevo Testamento. Visión general”. In: GARCÍA-LOMAS, J. M.; GARCÍA-MURGA, J. R. (Eds.). El seguimiento de Cristo. Madrid: Promoción Popular Cristiana, 1997, pp. 21-22.

Vera Ivanise Bombonatto

Doutora em Teologia pela Faculdade de Teologia Nossa Senhora da Assunção São Paulo / SP - Brasil E-mail: vera.bombonatto@paulinas.com.br

Recebido em: 07/10/17

Aprovado em: 21/02/18 